\title{
EMERGENCY RESPONSE TIME ON FRACTURES LOWER EXTREMITY SURGERY: A Technical Note
}

\author{
'Yunus, ${ }^{2 E}$.M. Rosa, ${ }^{2 F}$. Arofiati \\ 'Master of Hospital Administration Post Graduate Program \\ University of Muhammadiyah Yogyakarta, Prof. R. Soeharso \\ Orthopaedic Hospital Surakarta \\ 2Lecturer at University of Muhammadiyah Yogyakarta \\ Hospital Administration Program
}

\begin{abstract}
Accidents that result in open fractures if not treated properly can lead to worse problems. The effectiveness of the response time in the emergency room (ER) of the hospital in the decision of surgery requires speed, and the accuracy of the results so as not to cause worse effects such as infection, disability, or even death. The primary goals of early fracture treatment are to sustain the patient's life and, second, to maintain normal leg anatomy and function. Some things that need to be considered in proper fracture management are (1) basic surveys covering airways, breathing, blood circulation, (2) minimizing pain (3) preventing ischemic reperfusion injuries, (4) eliminating and avoiding potential sources of pollution. Various research results show the importance of early treatment quickly and accurately so as not to cause problems that can cause disability, and even death for patients.
\end{abstract}

Key words: emergency response time, surgery, fracture, lower extremity 


\section{INTRODUCTION}

Most people suffer from accidental injuries due to the impact of technological developments such as land transportation, mining, technology-intensive industries and heavy equipment at work sites, and the incidence of severe trauma remains high. Epidemiological data show that the number of traumatic injury sufferers worldwide exceeds 10 million each year [1], most of them died from severe trauma. Global Status Report On Road Safety 2018 $\mathrm{WHO}$, the death rate due to traffic accidents in the world from 2015 - 2018 is quite constant, namely around 1.35 million people in addition to an increase in the number of motorized vehicles and the number of human population[2].

Crash accidents often result in injuries with fractures. The severity of the fracture usually depends on the force causing the fracture. If the fracture point is exceeded only slightly, the bone may fracture rather than break completely. If the force is extreme, such as in a car accident or gunshot, bones can break. If a bone is broken in such a way that a fragment of bone protrudes through the skin, or a cut penetrates into the broken bone, it is called an "open" fracture. This type of fracture is very serious because once the skin is damaged, infection of the wound and bone can develop.

Post-impact care is the most important immediate action, with special techniques aimed at reducing severity. The Emergency Room (ER) is a hospital unit that provides early screening procedures for emergency patients to save lives and prevent further disability. What determines the success of a patient's rescue is the response time. Response time is the speed with which a patient is treated since the patient arrives for medical services in a matter of minutes. A good response time for patients in accordance with the minimum service standards at the Minister of Health of the Republic of Indonesia Number 129 of 2008 is $<5$ minutes. Hospital response time is one indicator of service quality which is an indicator of the process of achieving results [3].

Orthopedic surgery emergency cases in open fractures at Prof. Orthopedic Hospital. Dr. R. Soeharso Surakarta in 2019 there were 4801 emergency cases, which were operated on with Pre Decision and ERT 2 totaling 261 patients, a total of 148 patients with open lower limb fractures and 85 patients with open lower limb fractures of degrees I and II. The response time speed of 261 patients with an average predecision response time from the patient coming to the ER until getting an operation decision from an orthopedic doctor, an anesthetist and the consent of the patient's family, the average time was 84.59 minutes and ERT 2 was less than 120 minutes that was 95.5 minutes $[4]$.

This article reviews how to manage the timing of a medical emergency by looking at open fracture problems in the ER based on studies conducted prior to the writing of this article. Based on the high incidence of trauma and fractures as well as the serious complications that patients will experience if these events are not handled properly, one of them is knowing 
the condition of the fracture that can be given. treatment is faster, accurate and complete. A good baseline survey ( $A B C D E)$ is required to save lives and an adequate second survey to save limb function.

\section{Fracture Ekstremity Classifications}

Some of the pictures below show an overview of open fractures in several incidents that have received intensive care at Prof. Orthopedic hospital. Dr. R. Soeharso Surakarta in the 2019 period.

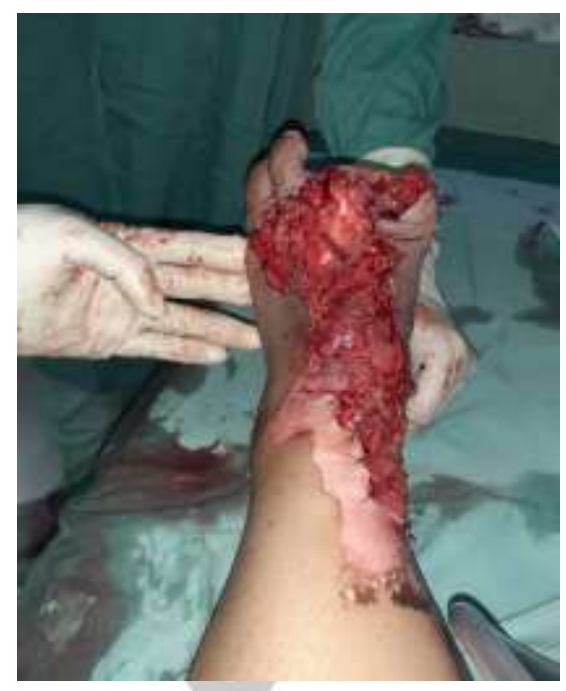

Figure1. Open Fracture Of Left Distal Tibia Fibula Gustilo Anderson Grade 3A
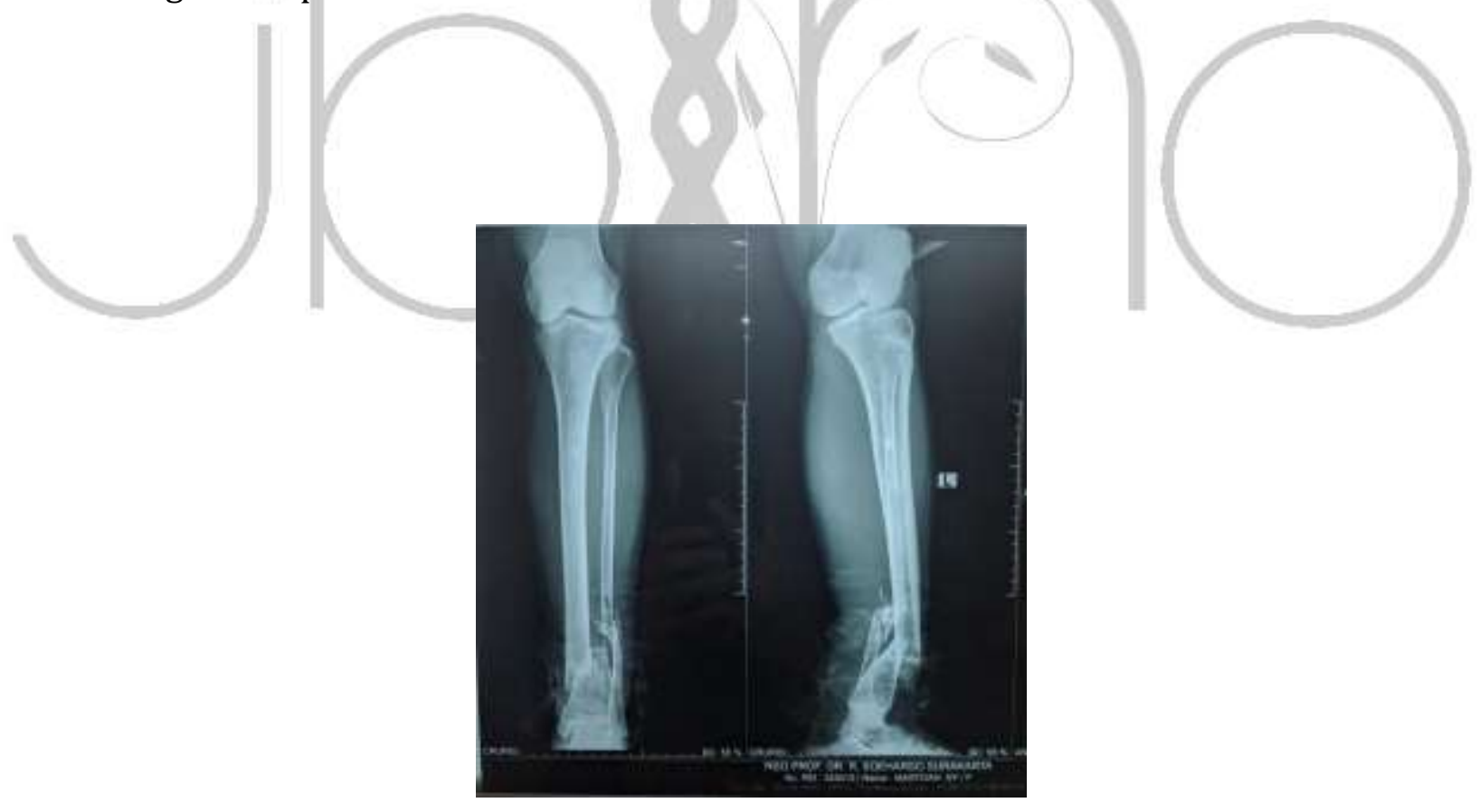

Figure 2. Fracture Tibia Fibula Distal Sinistra 


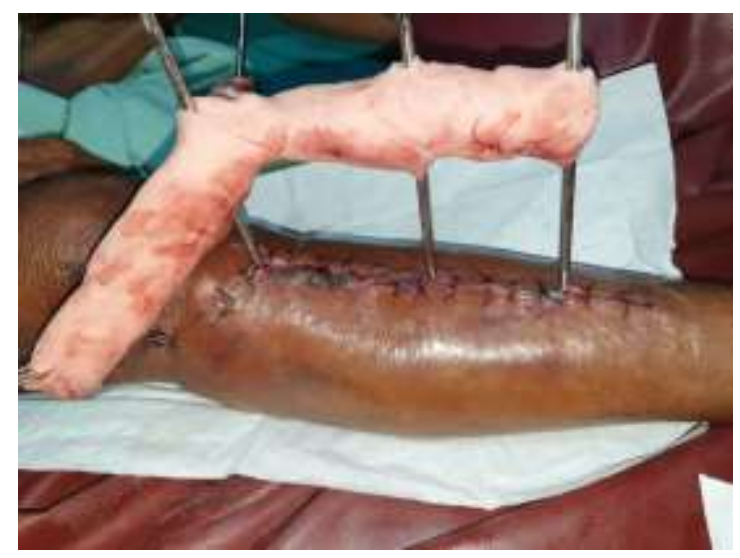

Figure 3. Post operative external fixation of tibia fibula dextra

A fracture is defined as the loss or disruption of the integrity of the bone, including injury to the bone marrow, periosteum, and surrounding tissue ${ }^{[5]}$. An extremity fracture is a fracture that occurs in the bones that form the location of the upper limb (radius, ulna, carpal) and lower limb (pelvis, femur, tibia, fibula, metatarsal). The classification of open fractures is classified into three types, namely[6]:

1. Type I: The wound is smaller than $1 \mathrm{~cm}$, clean and caused by bone fragments penetrating the skin.

2. Type Il: wound size between $1-10 \mathrm{~cm}$, uncontaminated and without major soft tissue injury.

3. Type III: Wounds larger than $10 \mathrm{~cm}$ with significant soft tissue damage. Type III is also divided into several subtypes:

a.IIIA: The wound has enough tissue to cover bone without requiring flap coverage.

b.IllB: extensive tissue damage necessitates local or distant flap coverage.

c.IIIC: Any fracture causing arterial injury that requires immediate repair.

\section{Diagnosis of Fractures of the Extremity}

To diagnose a fracture, a history can be performed first of all from both the patient and the patient introduction. The information that was explored was the mechanism of injury, whether the patient had a previous injury or fracture. Patients with tibial fractures may complain of pain, swelling and an inability to walk or move, whereas in fibular fractures the patient may complain of the same unless the patient may still be able to move [7].

Apart from anamnesis, physical examination is also important. The physical examination required can be grouped into three groups, namely look, feel, and move. First look or inspect where to observe the appearance of the injury, whether there is an open fracture (visible bone contact with outside air). Are visible deformities of the limbs, hematoma, swelling, etc. The second thing to pay attention to is feel or palpation. Palpation should be performed for all extremities from proximal to distal including joints proximal and distal to the injury to assess areas of pain, effusion, or crepitus. Often there will be other injuries that coincide with the main injury. The third 
point to assess is move. Assessment is carried out to determine ROM (Range of Motion) ${ }^{[10]}$. Often ROM examination cannot be done because of the patient's pain but this must still be documented[12].

Examination of the extremities should also cover the vascularity of the extremities including color, temperature, perfusion, sensation of the pulse, capillary return (normally $<3$ seconds) and pulse oximetry. A detailed neurological examination should also document sensory and motor function [11]. Depending on the patient's condition, a chest X-ray can be done. In radiological examination for injuries and fractures, the rule of $2 s$ is applied, namely[1]: 1) Two points of view, 2) Two joints, 3) Two extremities, and 4) Two times.

\section{Emergencies in Extremity Fractures in Emergency Room (ER)}

The main goal in the initial management of fracture is to preserve the patient's life and secondly to maintain both the anatomy and function of the limb as normal. The methods for emergency fractures are described in accordance with the operational standards of emergency services, including: (1) primary survey covering Airway, Breathing, Circulation, Disability, and Exposure, (2) Secondary surveys such as minimizing pain, preventing ischemia-reperfusion injuries, and prevent potential sources of contamination. When all of the above has been achieved, the fracture can be reduced and repositioned so as to optimize the condition of the bone for the bone grafting process and minimize further complications[15]. Orthopedic Hospital. Prof. Dr. R. Soeharso been carried out the emergency method according to the director's decision no 212 dated March 20, $2017^{[16]}$.

\section{Primary Survey}

After the patient arrives in the Emergency Room (ER), the first thing to do is to secure and apply the ABCDE principle (Airway, Breathing, Circulation, Disability Limitation, Exposure) [17].

a. A: Airway, with cervical control. The first thing to be assessed is the smoothness of the airway. This includes checking for airway obstruction by the presence of a foreign body or facial fractus. Attempts to free the airway must protect the cervical bone, therefore the Jaw Thrust technique can be used. Patients with impaired consciousness or GCS less than 8 usually require definitive airway insertion [17].

b. B: Breathing. After securing the airway it must further ensure proper ventilation. Good ventilation includes proper function of the lungs, chest wall and diaphragm. Some sources suggest that patients with significant lower extremity fractures should be given high flow oxygen 15 I / $\mathrm{m}$ via a non-rebreathing mask with a reservoir bag [15][17].

c. C: Circulation. When evaluating circulation, concern is the blood volume, bleeding, and cardiac output. Bleeding is often the main problem in fractures, especially open fractures. Femur fractures can cause blood loss in the thigh $3-4$ units of blood and create class III shock. It is best to stop bleeding by using direct pressure and raising the site or limb 
that was bleeding above body level. A good splint can significantly reduce bleeding by reducing movement and increasing the effect of tamponade of the muscles around the fracture. In open fractures, the use of sterile compressive dressings can generally stop bleeding. Aggressive fluid replacement is essential in addition to stopping bleeding ${ }^{[17]}$.

d. D: Disability. Towards the end of the primary survey a brief evaluation of the neurological condition is undertaken. assessed here are level of consciousness, pupil size and reaction, signs of lateralization and degree of spinal injury[17].

e. E: Exposure. the patient must be completely undressed, along with cutting, in order to examine and evaluate the patient. after the clothes are removed, it is important that the patient is enveloped so that the patient is not hypothermic [17].

Additional examinations in patients with musculoskeletal trauma such as fractures can be done, among others[17]:

a. Fracture Immobilization

The goal of fracture immobilization is to straighten the injured limb in the asanatomic position as possible and prevent excessive movement of the fracture area. this will be achieved by exercising traction to straighten the extremities and being maintained by means of immobilization. Using the splint correctly will help stop bleeding, reduce pain, and prevent further soft tissue damage. Immobilization should cover the joints above and below the fracture.

Femur fractures were temporarily immobilized with a traction splint. The traction splint pulls the distal part of the ankle or through the skin. Proximal to the traction splint is pushed into the groin through a ring pressing against the buttocks, perineum and groin. The simplest way to splash a traumatized leg is with the other leg. For knee injuries, wearing a long leg splint or cast can help provide comfort and stability. Limbs should not be immobilized in full extension. Tibial fractures should be immobilized with cardboard or metal gutter, long leg splint. If available, immobilized casts can be placed covering the lower legs, knees and ankles.

b. Radiology Examination

In general, radiological examination of skeletal trauma is part of the secondary survey. the type and timing of the radiological examination to be performed is determined by the results of the examination, clinical signs, hemodynamic conditions, and the mechanism of trauma. AP pelvic radiograph should be performed as early as possible in multitrauma patients without hemodynamic abnormalities and in patients whose source of bleeding has not been determined.

2. Secondary Survey

Part of the secondary survey of patients with musculoskeletal injuries was the history and physical 
examination. The aim of the secondary survey is to look for other injuries that may occur in the patient so that none of them are missed and untreated. If the patient is conscious and can speak, then we must take a history of AMPLE from the patient, that meants Allergies, Medication, Past Medical History, Last Ate and Event (incident or accident mechanism). It was important to ask the mechanism of the accident to find out and predict what injuries the patient has, especially if we still suspect that there is an injury that was not known during the primary survey.

Apart from a history of AMPLE, it is also important to seek information about treatment before the patient arrives at the hospital[14][15]. In the physical examination of the patient, several things that are important to evaluate are (1) the skin that protects the patient from fluid loss and infection, (2) neuromuscular function circulation status, (4) ligament and bone integrity. How to check it can be done by Look, Feel, Move. On Look, it can be judged on color and perfusion, cuts, deformities, swelling, and bruises. An internal inspection assessment is necessary for active external bleeding, as well as the back. Pale, non-pulsating distal part of the body indicates impaired vascularization. Swollen limb in the muscular area indicates a crush injury with threatening compartment syndrome. In the Feel test, we use palpation to check for areas of tenderness, neurological function, and crepitus. In the Move check we examine Range of Motion and abnormal motion [15][17].
Circulation examination is done by feeling the distal pulsation of the fracture and also examining the capillary refill at the fingertips and then comparing the diseased side with the healthy side. If hypotension complicates the examination of the pulse, a Doppler device can be used which can detect blood flow in the extremities. In hemodynamically normal patients, differences in pulse rate, coldness, pallor, paresthesias and the presence of motor disturbances indicate arterial trauma. Additionally an enlarged hematoma or bleeding radiating from an open wound indicates arterial trauma[17].

Neurological examination is also important to do considering that musculoskeletal injuries can also cause nerve fiber injury and nerve cell ischemia. Nerve function tests require the patient's cooperation. Each peripheral nerve with a large motor and sensory function needs to be systematically examined [17]:

The aim of further fracture management is to prevent potential sources of contamination in the fracture wound. There are several ways that can be done is to irrigate the wound with saline and cover the fracture with moist sterile ghas or you can also give betadine to the ghas. Give tetanus vaccination as well as antibiotics as a prophylactic for infection. Antibiotics that can be given are [12][15][17]:
a. The first generation of cephalosporins (cephalotin 1-2 9 divided by 3-4 times daily) can be used for Gustilo type I fractures.
b. Aminoglycosides (gram-negative 
antibiotics) such as gentamicin (120 mg 2x / day) can be added for type II and type III Gustilo classification.

c. Metronidazole $(500 \mathrm{mg}$ dose 2x / day) can be added to treat anaerobic bacteria.

Antibiotics can be continued for up to 72 hours after the wound is closed. Wound debridement in the operating room should also be performed before 6 hours posttraumatically to avoid posttraumatic sepsis[12]. Reduction, repositioning and immobilization according to anatomical position can wait until the patient is ready for surgery unless a neurovascular deficit was found on examination. If there are indications for repositioning due to neurovascular deficits, it is advisable to carry out repositioning in the ER using adequate analgesic techniques [15].

There are several options for analgesia techniques for the management of lower limb fracture patients in the ER. For patients with isolated tibia or ankle fractures, inhaled nitrous oxide and oxygen may be useful for manipulation, splintage and patient transfer[15]. In the strategy of relieving acute pain, if it is severe in fractures, the WHO "Three Step Analgesic Ladder" strategy is used. In acute pain, strong analgesics such as strong opioids should be given at first[18]. The dose of morphine is $0.05-0.1 \mathrm{mg} / \mathrm{kg}$ given intravenously every $10 / 15$ minutes by titration until it has an analgesic effect. There is recent evidence that in recent years Ketamine can also be used as an analgesic agent at low doses $(0.5-1$ $\mathrm{mg} / \mathrm{kg}$ ). This drug must also be irritated to achieve optimal response so as not to cause anesthetic effects. The beneficial effect of ketamine is that ketamine does not cause respiratory depression, hypotension, and causes bronchodilator effects at low doses. The disadvantage of ketamine is that it can induce delirium, but it can be prevented by prior administration of a benzodiazepine (0.5-2 mg midazolam intravenously)[15]. Peripheral nerve blocks are also an option, either alone or in combination with intravenous analgesics, the ones commonly used are femoral nerve blocks[15].

3. Standard Operating Procedures (SOP) for Emergencies on Extremity Fractures in the Emergency Room (ER) of Orthopedic Hospital Prof.Dr. R. Soeharso surakarta

Based on Standard Operating Procedures at RSO. Prof.Dr. R. Soeharso Surakarta applies emergency case service procedures in the ER for emergency patients. Where in its implementation, it must refer to the SOP, namely the Emergency Response Time [16].

a. Pre Decision

Pre Decision is the time needed by patients starting from entering the emergency room until getting a diagnosis and action decision from the doctor in charge (from arriving to decision), in practice the Pre Decision time is 90 minutes from when the patient arrives at the ER until he gets a decision for action (DPJP Orthopedics), Anesthetist and family).

b. Emergency Response Time The time it takes for emergency 
room patients to get cito surgery. Starting from the decision to operate by the doctor in charge (DPJP) until the start of the incision in the operating room (from decision to incision).

In its implementation, it is necessary to have criteria in determining whether these patients are included in emergency patients (cito) or not, namely based on [16]:

1) Management of emergency patients according to emergency priorities.

2) Patients who are decided to receive cito surgery are operated on within 120 minutes counting from the time of decision making (DPJP decision) to the incision.

3) Inclusion criteria: emergency room patients who were decided cito action

4) Exclusion criteria: open fracture cases that exceeded the golden period ( 8 hours). The patient is accompanied by other organ emergencies that require regulation / improvement of the condition and the patient is decided to require fasting for more than 2 hours.

Steps for Implementing Emergency Response Time (ERT) in the Emergency Room [16].

Step 1. Preoperative preparation including clinical examination, supporting examinations (radiology, laboratory), DPJP consultation (orthopedic, anesthetist, other specialists) and informed consent is done for 90 minutes.

Step 2. The IGD coordinates with the IGD Operating Room for registration of a cito operation plan

Step 3. The Operations Room performs the scheduling and preparation of infrastructure and human resources with priority operations

Step 4. Preparation of infrastructure advice for at least 2 sets of basic surgery, and activation of human resources on standby if needed

Step 5. Emergency Response Time (ERT 2) for the cito operation, which is 120 minutes starting from the moment of decision making for the surgery to the incision on the operating table (from decision to incision).

Step 6. Data collection is carried out for one month, reported to the Director of Medical and Nursing

Step 7. Sources of data from patient medical records

Step 8. Emergency Response Time 2 formula, which is the amount of time it takes for the patient to get cito surgery (numerator) divided by the number of all emergency room patients who are decided by cito surgery (denumerator)

Emergencies Related to Fractures

1. Artery Massive Bleeding

Sharp or blunt trauma that damages a joint or bone near an 
artery can produce arterial trauma. This injury can cause large bleeding in the open wound or bleeding in the soft tissue. Cold, pale extremities, and disappearance of limb pulses indicate impaired arterial blood flow. Hematoma that enlarges rapidly, indicating vascular trauma. This injury becomes dangerous if the patient's hemodynamic condition is unstable [17].

If a large artery trauma is suspected, it should be consulted immediately to a surgeon. Management of large artery bleeding includes direct pressure and aggressive fluid resuscitation. Shock can occur due to a lack of blood volume due to massive bleeding.

Some things that can be done when signs of shock are found (pulse increases and decreases, blood pressure decreases, cold akral, decreased consciousness) are:

a. Airway and breathing are carried out by installing airway aid if necessary and administering oxygen.

b. Circulation, namely by splitting the bleeding site with, installing vascular access, and initial fluid therapy. For vascular access, two large IV catheters (minimum no 16) are installed. The best places to place a venous access are in the forearm vein and in the cubital, but central venous catheter placement is also indicated if facilities are available. For initial fluid therapy, a warm fluid bolus is given as soon as possible. The usual dosage is 1 to 2 liters for adults and $20 \mathrm{ml} / \mathrm{kg}$ for children. Crystalloid fluids such as RL or NS are used for initial fluid selection. The patient's response was then observed during the initial fluid administration. The calculation is the administration of $3 \mathrm{~L}$ of crystalloid to replace $1 \mathrm{~L}$ of blood. Colloid administration can be considered if crystalloid administration is not sufficient to improve tissue perfusion [17].

c. Assessment of patient response can be done by monitoring several conditions such as: 1) vital signs (blood pressure, pulse, oxygen saturation) 2) Urine production is monitored by inserting a urinary catheter. The target urine output is $0.5 \mathrm{ml} / \mathrm{kg} / \mathrm{hr}$ for adults, $1 \mathrm{ml} / \mathrm{kg} /$ $\mathrm{hr}$ for children. 3) acid-base balance [17].

d. When the patient's condition is stable, examination or referral must be done to definitively treat the cause of the bleeding.

2. Crush Syndrome

Crush Syndrome is a clinical condition caused by muscle damage, which if left untreated will lead to acute kidney failure. This condition occurs as a result of crush injury to the mass of a number of muscles, the most common being the thigh and calf. This condition is caused by impaired muscle perfusion, ischemia, and myoglobin release[17].

The pathophysiology of crush syndrome begins with trauma or other etiology that causes muscle ischemia. Extensive muscle trauma such as to the thigh and leg by blunt trauma is one of the most common causes of crush syndrome. Crush syndrome usually 
occurs during disasters such as earthquakes, terror bombs and others where muscles and body parts are crushed by a heavy object[18]. In normal circumstances the plasma myoglobin level is very low 10 to 0.003 mg per $\mathrm{dl}$ ). When more than 100 grams of skeletal muscle have been damaged, myoglobin levels exceed myoglobin binding capacity and will interfere with glomerular filtration, obstructing renal tubules and lead to renal failure[18].

Crush syndrome symptoms include pain, stiffness, cramps, and swelling of the affected muscle, followed by weakness and loss of muscle function. Tea-colored urine is a fairly typical symptom because the urine contains myoglobin. Diagnosing crush syndrome is often overlooked when the disease is not suspected from the start[18]. The complications are hypovolemia, metabolic acidosis, hyperkalemia, acute renal failure, and DIC (Disseminated Intravascular Coagulation) ${ }^{[17]}$.

Prompt and prompt emergency management is required in the management of crush syndrome and prevention of its complications. In the Emergency Room that can be done are[18]:

a. $A B C$ evaluation

b. Administration of IV fluids. Fluid resuscitation is urgently needed given hypovolemia frequently occurs. Administration of normal saline at a rate of 1.5 liters per hour and the target is urine production of $200-300 \mathrm{ml}$ per hour. Giving fluids containing potassium and lactate should be avoided because it will worsen hyperkalemia and acidosis. In-depth investigation of trauma and monitoring of the patient's condition.

c. Giving bicarbonate to treat acidosis

d. Once the hemodynamic state is stable, definitive therapy for causes such as trauma can be performed.

3. Compartment Syndrome

Compartment syndrome can be found in places where the muscle is limited by a closed fascial cavity. Keep in mind that the skin also functions as a barrier layer. The areas commonly affected are the lower legs, forearms, feet, hands, gluteal region, and thighs. Ischemia may occur due to increased compartment content due to edema arising from secondary revascularization of an ischemic limb or due to shrinkage of the compartment contents due to external pressure eg compressive dressing [17].

The symptoms and signs of compartment syndrome are[17]:

a. Pain increases and especially increases with passive movements that stretch the muscle in question

b. Paresthesia of the distribution of the affected peripheral nerves, decreased sensation or loss of function of the nerves passing through the compartment.

c. Asymmetry in the compartment area

Paralysis or muscle paresis and loss of pulse (caused by compartment pressure exceeding systolic pressure) are advanced stages of compartment syndrome. The clinical diagnosis is based on a history of trauma and a 
physical examination. Intracompartment pressures exceeding 35$45 \mathrm{mmHg}$ lead to decreased capillary flow and muscle and nerve damage due to anoxia[17].

Management of compartment syndrome includes removing all pressing dressings, casts and splints. Patients should be monitored and examined every 30-60 minutes. If there is no improvement, a fasciotomy is necessary[17].

\section{CONCLUSION}

Fracture or fracture is defined as loss or impairment of the integrity of the bone, including injury to the bone marrow, periosteum, and surrounding tissues. To diagnose a fracture, a history can be performed first of all from both the patient and the patient introduction. The information obtained was the mechanism of injury, whether the patient had a previous injury or fracture. The physical examination required can be grouped into three groups, namely look, feel, move. Are visible deformities of the limbs, hematoma, swelling, etc.

Fracture or fracture is defined as loss or change in bone integrity, including damage to the bone marrow, periosteum and surrounding tissue. To diagnose a fracture, a history can be obtained in advance from the patient and the patient's presentation. Information obtained is in the form of injury mechanism, if the patient has experienced previous injuries or fractures. The necessary physical examinations can be grouped into three groups: appearance, sensation, and movement. Detects limb defects, bruises, inflammation and more.

Palpation is used to diagnose areas of pain, stroke, or fracture. Motion analysis is performed to determine ROM (distance to motion). Examination of the extremities should also include limb involvement, including color, temperature, perfusion, pulse sensation, capillary return (usually $<3$ seconds), and pulse oximetry. As a diagnosis to aid in the diagnosis, radiological examinations / X-rays are used. In radiological examinations of injuries and fractures, two arrangements occur, namely: two perspectives, two joints, two extremities, and two.

The primary goals of early fracture treatment are to sustain the patient's life and, second, to maintain normal leg anatomy and function. Some things that need to be considered in proper fracture management are (1) basic surveys covering airways, breathing, blood circulation, (2) minimizing pain (3) preventing ischemic reperfusion injuries, (4) eliminating and avoiding potential sources of pollution.

In the main survey, what had to be guaranteed before admitting a patient was $A B C D E$ (airway, respiration, circulation, disability and exposure). If $A B C$ is safe, early treatment can be given. Immobilization of the leg with suspected fracture; The spinal cord is usually used as a simple initial immobilization. After the primary survey, a second survey was carried out, covering sufficient history, complete physical examination, radiological examination, wound irrigation, and pain relief. and antibiotics. Many of the anxiety conditions resulting from leg fractures can be fatal, especially vascular (large vein) injuries, crush 
syndrome and compartment syndrome. This condition must be recognized and treated promptly and accurately in order to maintain an important and functional patient prognosis.

\section{REFFERENCES}

1. Yuniarti, Nur. 2013. Epidemologi Trauma Secara Global, e-Jurnal Medika Udayana Vol. 2 No. 10, 1749-1762. available at https://ojs.unud.ac.id/index.php/eum, 29-09-2020.

2. [WHO], 2018. Global Status Report On Road Safety. available at https://www.who.int/data/gho/data/th emes/road-safety, accesed 29-09-2020.

3. [Kepmenkes], 2008. Standar Pelayanan Rumah Sakit, available http://bprs.kemkes.go.id/vl/index.php, accesed 29-09-2020.

4. LAKIP, 2019. Laporan Akuntabilitas Kinerja Instansi Pemerintah tahun 2019, Instalasi Gawat Darurat Rumah Sakit Ortopedi Prof. Dr.R.Soeharso Surakarta.

5. Moran DS, Israeli E, Evans RK, Yanovich $R$, Constantini $N$, Shabshin $N$, et al. Prediction model for stress fracture in young female recruits during basic training. Med Sci Sports Exerc. Nov 2008;40(11 Suppl):S636-44.available at https://pubmed.ncbi.nlm.nih.gov/18849 871/, accesed 29-09-2020.

6. Gustilo RB, Merkow RL, Templeman D. The management of open fractures. J Bone Joint Surg Am. Feb 1990;72(2):299304 available at https://pubmed.ncbi.nlm.nih.gov/24062 75/, accesed 29-09-2020.

7. Norvell J G, Kulkarni R. Tibial and Fibular Fracture.

Available http://emedicine.medscape.com/articl e/826304-overview, 29-09-2020.

8. Corso P, Finkelstein E, Miller T, Fiebelkorn I, Zaloshnja E. Incidence and lifetime costs of injuries in the United States. Inj Prev. Aug 2006;12(4):212-8. Available at https://pubmed.ncbi.nlm.nih.gov/16887 941/, accesed 29-09-2020.

9. Canale, 2003. ST. Campbell's Operative Orthopaedics. 10 $10^{\text {th }}$ ed. St Lovis, Mo: Mosby-Year Book.

10. Court-Brown CM, Rimmer S, Prakash U, MCQueen MM. The epidemiology of open long bone fractures. Injury. Sep 1998;29(7):529-34. Available at https://pubmed.ncbi.nlm.nih.gov/10193 496/, accesed 29-09-2020.

11. Buckley R dkk. General Principle of Fracture Workup. Available at http://emedicine.medscape.com/articl e/1270717-workup. accesed 29-09-2020.

12. Patel $M$ dkk. Open Tibial Fracture. Diakses

di http://emedicine.medscape.com/articl e/ 1249761-overview. accesed 29-092020.

13. American College of Surgeons [ACS], 2004. Advanced Trauma Life Support for Doctors (ATLS): Student Course Manual. $7^{\text {th }}$ ed. Chicago, III: American College of Surgeons.

14. Wang AM, Yin X, Sun HZ, DU QY, Wang ZM. Damage control orthopaedics in 53 cases of severe polytrauma who have mainly sustained orthopaedic trauma. Chin J Traumatol. Oct 2008;1 1 (5):283-7.

15. Lee C, Porter KM. Prehospital Management of Lower Limb Fracture. Emerg Med J 2005;22:660-663. Available at https://europepmc.org/article/med/161 13195, accesed 29-09-2020. 
16. SOP, 2017. Standar Prosedur Operasional tentang Emergency Respon Time 2. Rumah Sakit Ortopedi Prof. Dr. R. Soeharso Surakarta.

17. American College of Surgeons Comittee on Trauma. Advanced Trauma Life Support for Doctors (ATLS) Student Course Manual. $8^{\text {th }}$ ed. Chicago, IL : American College of Surgeons; 2008.

18. Khan F.Y. Rhabdomyolysis : A Review of the Literature. The Netherlands Journal of Medicine. Oct 2009; 67(9); 272 - 283, available at https://pubmed.ncbi.nlm.nih.gov/19841 484/, accesed 29-09-2020. 